\title{
Understanding eParticipation Services in Indonesian Local Government
}

\author{
Fathul Wahid ${ }^{1,2}$ and $\emptyset y s t e i n ~ S æ b ~ \emptyset^{2}$ \\ ${ }^{1}$ Department of Informatics, Universitas Islam Indonesia, Yogyakarta, Indonesia \\ ${ }^{2}$ Department of Information Systems, University of Agder, Kristiansand, Norway
}

\begin{abstract}
This study aims at understanding how local government from a developing country, in this case Indonesia, implement and manage eParticipation services. In doing so, we combine institutional theory and stakeholder theory to build a sharper analytical lens. From an interpretive case study in the city of Yogyakarta, we reveal the institutionalization process of the services since their inception and identify major stakeholders and their salience. Based on our findings, we propose implications for practice and suggest implications for further research. Future work, based on a multiple case strategy including several eParticipation cases from other parts of Indonesia, will further explore the findings reported here.
\end{abstract}

Keywords: eParticipation, eGovernment, Stakeholder Theory, Institutional Theory, Institutionalization, Developing Country, Indonesia.

\section{Introduction}

In recent years, eParticipation services have proliferated in local governments, influencing on the communication between governments, politicians and citizens. As society becomes ever more digitized, governments are attempting to boost democratic interests through various eParticipation services [1,2]. Triggering the interests of stakeholders is vital in eParticipation efforts. Through such services, citizen can communicate easily with local government through various channels to increase citizens' participation [3-5]. In general, eParticipation includes technology-mediated interaction between the civil society, politicians and administration [6].

While the initiatives are promising in promoting citizen participation, there is lack of research aiming at understanding the phenomenon and eventually accessing its impact in decision-making quality in the context of developing countries. Moreover, citizen participation in developing countries are very low compared to developed countries [7]. Hence, this research seeks to answer an explorative question: how does Indonesian local government implement and manage eParticipation services?

In Indonesia, during the 'new order' of Suharto regime (1965-1998), government decisions were entirely limited to government officers, especially high-level bureaucrats. Citizen participation was restricted, if not discouraged, as the central government neglected local demands and problems [8,9]. After the fall of the Suharto 
regime, citizens could freely articulate their opinions. Citizen participation in the Indonesian context becomes even more important after decentralization in 2001 when some of the national government authorities were delegated to the local government [9], encouraging the development of local and contextualized policies.

In order to answer our research questions, we conducted a case study that traces back the implementation of eParticipation services in the city of Yogyakarta since its inception in 2003. Yogyakarta is among the pioneers in the provision of eParticipation services. The study is framed within the concepts of institutional theory and stakeholder theory. Both theories have been used in information system (IS) studies for various purposes [10-12]. Institutional theory helps to understand the institutionalization process of eParticipation services and identifying institutional actors. Stakeholder theory (ST) further expands our understanding of the actors, by identifying their salience and connections between them. By combining the two, we develop a sharper theoretical lens to better understand the phenomenon under study.

The remainder of the paper is organized as follows. Next, we introduce theoretical premises for the study before we describe the research setting and method. Then we present findings followed by the discussion, before reflecting on limitations and contributions.

\section{Theoretical Premises}

\subsection{Institutional Theory}

Institutional theory sees institutions as "multifaceted, durable social structures made up of symbolic elements, social activities, and material resources" [13]. It offers rich concepts to study institutional effects of IS (e.g. eParticipation services in this study), institutionalization, and interactions between IS and institutions [10]. The concepts include institutional isomorphism [14], institutional logics [15], institutionalization [16], and institutional entrepreneurship [17, 18].

Institutional theory is relevant to our study for two reasons. First, eParticipation services can be seen as institutions, provided they have been widely accepted and have become an integral part of day-to-day practices. Second, institutional theory can be used to explain the history of IS implementation [19], which in this proposed study is the institutionalization of an eParticipation services. The theory is useful to understand how institutional transformation takes place [20]. In Selznick's [21] words, "institutional theory traces the emergence of distinctive forms, processes, strategies, outlooks, and competencies as they emerge from patterns of organizational interaction and adaptation". Previous studies [22-24] in eGovernment have successfully used institutional theory to understand various phenomena.

\subsection{Stakeholder Theory}

The theory of stakeholder salience [25] offers sound theoretical arguments to explain why some stakeholders are salient, whereas others are not, depending on the 
relationship between power, legitimacy and urgency (Figure 1). The sum of the attributes determines the salience of a stakeholder, where definitive stakeholders possess all three attributes and are more salient than those who possess only one or two of the attributes. Mitchell et al. [25] argued for a numeric understanding of these attributes to identify whether stakeholders have, or have not, power, legitimacy and urgency. Recent work within the eGovernment area has successfully applied the salience perspective with a more narrative approach $[11,12,26]$, more in line with the approach applied in our study.

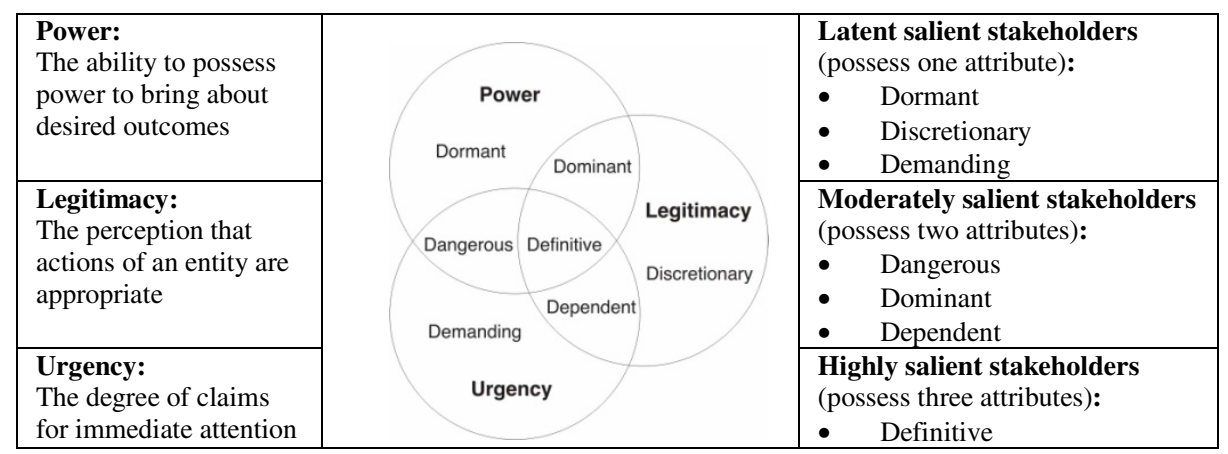

Fig. 1. Attributes determining a stakeholder's salience Source: Adapted from Mitchell et al. [25]

Stakeholder salience analyses have been introduced to explain stakeholder actions in eParticipation efforts [27]. Stakeholder analysis is introduced here for two reasons. First, it helps to identify actors being involved or influencing on the initiative. Second, it sheds lights on stakeholders's salience. Thus, stakeholder analysis may help to identify whom to include, whom to pay attention to, and whom who may have the possibility to influence, negatively or positively on the initiative.

\section{Research Setting and Method}

\subsection{The Case}

The eParticipation service under study was initiated in the city of Yogyakarta in 2003. At that time, the mayor intended to improve public services by providing a hotline service enabling the public to send messages directly to the local government, by phone calls or SMS messages. Yogyakarta collaborated with a national telecommunication company to provide a special easy-to-remember number (2740) for receiving SMS messages. Incoming messages were tabulated and responded manually. The service was under the responsibility of a One-roof Service Unit (Unit Pelayanan Terpadu Satu Atap [UPTSA]) which in 2006 became the Department of License (Dinas Perijinan). 
The system remained the same until 2013, due to the fact that UPIK did not have access to the source code, making it difficult to maintain and further develop the system. A new web-based version (http://upik.jogjakota.go.id), implemented late 2013, allows automated management of incoming messages. In implementing the system, Yogyakarta gained support from Swisscontact, an international development agency, which collaborated with PKPEK, a local NGO. Now, messages posted through a website or SMS are automatically registered. A Unit for Information and Complaint Services (Unit Pelayanan Informasi dan Keluhan [UPIK]) was then established to manage the system.

\subsection{The Method}

Our study is exploratory in nature, aiming to define questions, proposing new constructs and eventually construct new theoretical propositions, additional constructs and the relationships between constructs [28] that may complement the original framework [29]. Exploratory case studies typically address how and why questions concerning the dynamics present within a contextual setting [30].

In this paper, reporting from research in progress, we have interviewed seven informants: two administrators at UPIK, head of the Subsection for Application Development, head of UPIK, head of the Section for Information Technology, vice head of the Department of License, and the Mayor. Interviews at UPIK, conducted in November 2013, focused on the implementation and management of the services. Interviews with other informants, conducted in July and August 2011, covered a broader area of the use of information technology in Yogyakarta. Findings from the interviews were further enriched by consulting and analysing documents and information such as internal reports, presentation slides and news in the media.

Data were analysed based on concepts from institutional and stakeholder theory, such as institutional pressure, institutional logic, institutionalization, resource mobilization, power, urgency, and legitimacy.

\section{$4 \quad$ Findings}

The flow of incoming messages is illustrated in Figure 2. Citizens may send messages through various channels: SMS, website, e-mail, phone, fax, regular letter, or by visiting UPIK. Only messages retrieved through SMS and the website are automatically registered. The administrators at UPIK filter and forward messages to the appropriate technical department within 24 hours. The forwarded messages will be accessible online, as long as they are not considered sensitive (e.g. discussing corruption). The technical departments have two days to respond to ordinary messages, six days for more complicated issues. Some specific messages, such as those demanding for written public information, will be handled separately by the Managing Officer of Information and Documents (PPID).

Although an online web-based service has been in place for around ten years, SMS is still the most preferred channel (see Table 1). In 2004, 85\% of the incoming 
messages came through SMS, whereas only $1 \%$ through the website. Interestingly, $11 \%$ came through face-to-face meetings at the UPIK office. The picture changed slightly in 2006 , when $16 \%$ were sent through the websites, only to decrease down to $6 \%$ in 2010 . Now, SMS messages accounted for $94 \%$ of the total messages.

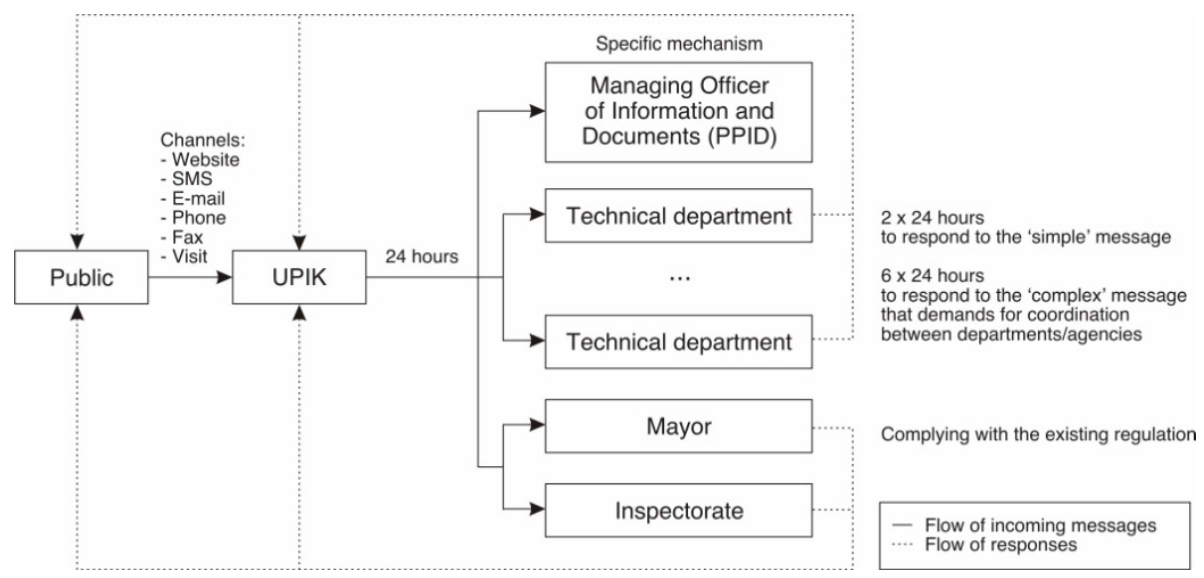

Fig. 2. Flow of incoming messages and responses

Table 1. Statistics of the incoming messages through various channels

\begin{tabular}{|l|r|r|r|r|r|r|r|r|r|r|r|}
\hline \multirow{2}{*}{ Channel } & \multicolumn{10}{|c|}{ Number of messages } \\
\cline { 2 - 13 } & 2004 & 2005 & 2006 & 2007 & 2008 & 2009 & 2010 & 2011 & 2012 & $2013^{*}$ & \multicolumn{1}{c|}{ All } \\
\hline SMS & 1,862 & 2,950 & 2,166 & 1,928 & 2,873 & 2,510 & 3,220 & 3,272 & 3,092 & 3,502 & 27,375 \\
\hline Website & 23 & 0 & 402 & 455 & 426 & 255 & 190 & 138 & 132 & 74 & 2,095 \\
\hline Phone & 34 & 4 & 0 & 0 & 1 & 0 & 4 & 5 & 1 & 4 & 53 \\
\hline Fax & 2 & 0 & 0 & 0 & 0 & 0 & 0 & 0 & 0 & 0 & 2 \\
\hline Email & 15 & 8 & 0 & 0 & 0 & 1 & 0 & 0 & 0 & 10 & 34 \\
\hline Visit & 236 & 291 & 0 & 0 & 0 & 0 & 0 & 0 & 1 & 3 & 531 \\
\hline Other & 13 & 0 & 1 & 2 & 1 & 0 & 0 & 3 & 1 & 5 & 26 \\
\hline Total & 2,172 & 3,253 & 2,568 & 2,383 & 3,300 & 2,766 & 3,414 & 3,415 & 3,226 & 3,598 & 30,095 \\
\hline
\end{tabular}

Notes: *Until November 2013.

Regardless of the channels used, the number of messages sent through the services indicates good acceptance among citizens, with a total of 30,000 messages received since 2004 until November 2013. The incoming messages are categorized (by UPIK) into four groups: complaints $(28.5 \%)$, questions (25.6\%), information $(31.7 \%)$, and suggestions (14.3\%). Around $90 \%$ of the messages have been responded.

\subsection{Institutionalization}

Institutional Pressure. The services, when initiated in 2003, were among the pioneers in Indonesia. External pressure came from the demand from the public for more transparent government, as asserted by the head of UPIK: 
"We are fully aware that the public of Yogyakarta are intelligent. This was one of the reasons [behind the establishment of the eParticipation services]. If we did not improve our transparency, we might easily become a target of the public criticism."

Institutional Logic. The intention was to provide communication channels enabling citizens to convey messages to local government, as a part of affirmative actions taken by the local government to improve public participation. The logic behind the services was to provide better services to the public. Such services were not only beneficial to the public, but also to local government. Expected benefits include: (1) increase citizens' role in controlling local government, (2) allowing government to collect public aspirations, and (3) as a result, enabling local government to design programs that accommodate the public aspirations. In general, the services enable local government to gain trust from the public. Lack of trust to government is among the chronic problem in the Indonesian context.

Institutionalization. A main challenge in the initiation phase of the implementation of the eParticipation services was to change the department heads mind-set. From the beginning, the mayor realized this challenge, and coped it with instilling values that would be important to guide the implementation of the services. The mayor lead by example, by spending substantial time to visit and discuss with citizens, and by sending messages and answers through the system. The mayor argued that the local government should have willingness to be controlled and corrected by the public. According to him:

"We have to make our position less sacred. It is only division of job. When we are talking about eGovernment, we do not pay attention to the social status. ... I am talking about how to work in more effective, efficient, transparent, and accountable ways. All are inseparable in good governance practices. eGovernment initiatives are taken for that purpose."

An administrative staff at UPIK confirmed the mayor's statement. He explained:

"The mayor would like to change the mind-set of government officers, from acting as 'pangreh praja' [those with power to command] to becoming 'pamong praja' [those who serve the people]. ... At that time, we were not ready to change ourselves."

Resource Mobilization. The mayor gained support from external and internal actors to improve the services. External actors include Swisscontact (an international development agency), PKPEK (a local NGO), a national telecommunication company, and more importantly, the public. Several initiatives were taken to make the public aware of the eParticipation service and to attract their support. Initiatives include the arrangement of public meetings at the village level, advertising in local newspapers and radio stations, distributing stickers, and placing banners in all the village and subdistrict offices.

Some internal resistance from the technical departments could be identified, primarily in the initiation phase. For instance, some incoming messages to the technical department were not answered. Then the mayor usually called the head of the respective technical department to solve the problem. The head of sub-section metaphorically described: "[The phone call from the mayor] is enough to make them sweating 
that morning." For the same purpose, every month, District Secretary (Sekretaris Daerah) sends a warning letter to the unresponsive technical departments. Close oversight is among of the strategies to mobilize support from internal stakeholders.

\subsection{Stakeholders and Their Salience}

Stakeholders. Table 3 summarizes our initial assessment of the involved stakeholders along with the level of salience related to their power, urgency, and legitimacy. The mayor is a driving force, as he insisted to implement the services and supervised the actions to make sure that the services run as expected. UPIK is established to manage the services and serves as a 'hub' or intermediary between the public and local government. Technical departments (including sub-district offices) are the 'busiest' stakeholders as they are responsive to the incoming messages. Section for Information Technology is the stakeholder responsible for procuring and maintaining the supporting system. Operators in each technical department are responsible for replying, routing incoming messages to the respective head of department and collecting responses from the targeted agencies.

Table 2. Stakeholders and their salience

\begin{tabular}{|l|l|l|l|l|}
\hline Stakeholder & Power & Urgency & Legitimacy & Salience \\
\hline Mayor & High & High & High & High \\
\hline UPIK & Medium & Medium & Medium & Medium \\
\hline Technical Department & Medium & Low/Medium & High & Medium \\
\hline Section for IT & Medium & Medium & Medium & Medium \\
\hline Operator & Low & Low & Medium & Low \\
\hline Public & Low & High & High & Medium/High \\
\hline
\end{tabular}

Stakeholder Salience. The mayor is a definitive stakeholder with high level of power, urgency, and legitimacy. UPIK and Section for Information Technology are definitive stakeholders though with a lower level of salience compared to the mayor. Public is dependent stakeholder as although they have high urgency and legitimacy, they lack (formal) power. So are the operators at the technical departments. Technical departments are dominant stakeholders since most of the incoming messages are addressed to them.

\section{Discussion}

Discussion is made in light of the research question stated in the outset: how does Indonesian local government implement and manage eParticipation services? In doing so, we focus on two intertwined aspects: the institutionalization process and the relationship between the stakeholders.

The eParticipation services are certainly collective initiatives and involve political decision-making. However, it is obvious that the role of the mayor was very influential, considering that, especially at the beginning, some stakeholders implicitly indicated reluctance to take part in the services. Here, we may consider that the mayor 
acted as institutional entrepreneur, who directed and led the organizational changes in implementing the services. In doing so, at the beginning, he cultivated values to the services beyond the instrumental utility of the services [31]. In addition, the mayors and his backers, mobilized resources and supports from other stakeholders (cf. [22]). A set of institutional logics was introduced to legitimate the services, to mobilize supports, and to guide the implementation.

Afterwards, the institutionalization was strengthened by typification process [13], where certain forms of responsibilities were associated with certain stakeholders who, in this case, have different level of salience. The only definitive stakeholder is the mayor. As a definitive stakeholder, he would be given attention not only because he represents a legitimate claim, but also since he is likely to exercise power because of a sense of urgency. A mayor will always possess legitimacy and power. Interestingly, the mayor of Yogyakarta also possessed urgency, based on his personal interest in the initiative. After implementation, a new mayor was elected possessing the same legitimacy and power, but less (personal) urgency to champion the initiative. Recent research [26] argues that salience, especially urgency, needs to be high for one or another key stakeholder at each phase of a project. Future analysis is needed to explore consequences of decreasing urgency from the definitive stakeholder.

The salient analyses further unveil the low salience of those being responsible for handling the request from the public, the operators. They have low urgency and power, and were not directly involved in development of the services. Without concerning "doers" interests, by involving them in the processes to increase their awareness and, consequently, their salience, the initiatives run the risks of operators giving less priority to providing answers. Moreover, the operators are highly dependent on the heads of technical department. Some of them also have low urgency. Hence, increasing the level of urgency of both the heads of technical department and the operators is important to improve and sustain the eParticipation services.

Although the public has low formal power, they are successful in giving institutional pressure to the local government due to strong support from the definitive stakeholder, the mayor. It is important to include the notion of informal power in this context, which will be part of future analyses. Furthermore, our study indicates the need for a more thoroughly analysis of the public, to further expand our understanding of differences between various groups and the level of salience; such as activist citizens, consumer citizens, local businesses, NGOs and so on. For example, it will be important to understand why the number of incoming messages only changed slightly from 2004 to 2013 (see Table 1).

\section{Conclusion}

We revealed that the eParticipation services are collective initiatives that need resource or support mobilization from various stakeholders. The salience level of the involved stakeholders to some extent has impact on how they perceive the services and take a part in the implementation process. To act as institutional entrepreneur, a stakeholder needs to have a certain level of salience in three aspects (power, urgency, and legitimacy). With all the three qualities, combined by a set of strategies to mobilize resources, the mayor acted as the institutional entrepreneur who drove the organisational changes. 
The main contributions of this paper are twofold. First, it reports the implementation of eParticipation services from the context of a developing country, which so far, is under-researched and less articulated in the extant literature. We expect to fill this void. Second, it makes a first attempt to combine two theories to build a sharper analytical lens, but with recognizing their distinct contributions, which complement to each other. For example, Clegg [32] suggests to bring back the discussion of power into institutional theory.

However, as a research in progress, we cannot provide a complete picture, and hence, we need to delve further to better understand the situated practices of each stakeholder. We will collect additional data from Yogyakarta by involving more stakeholders, and include cases from other parts of Indonesia. By doing so, we expect to provide a fuller picture on how eParticipation services are implemented in different contexts of developing countries and how to harvest such services to improve the quality of public participation.

\section{References}

1. Macintosh, A., McKay-Hubbard, A., Shell, D.: Using weblogs to support local democracy. In: Böhlen, M.H., Gamper, J., Polasek, W., Wimmer, M.A. (eds.) TCGOV 2005. LNCS (LNAI), vol. 3416, pp. 1-12. Springer, Heidelberg (2005)

2. Tambouris, E., Liotas, N., Tarabanis, K.: A framework for assessing eParticipation projects and tools. In: Proceedings of the 2007 Hawaii International Conference on System Sciences (2007)

3. Effing, R., van Hillegersberg, J., Huibers, T.: Social media and political participation: Are Facebook, Twitter and YouTube democratizing our political systems? In: Tambouris, E., Macintosh, A., de Bruijn, H. (eds.) ePart 2011. LNCS, vol. 6847, pp. 25-35. Springer, Heidelberg (2011)

4. Jackson, N.A., Lilleker, D.G.: Building an architecture of participation? Political parties and Web 2.0 in Britain. Journal of Information Technology \& Politics 6, 232-250 (2009)

5. Kalnes, Ø.: Norwegian parties and Web 2.0. Journal of Information Technology \& Politics 6, 251-266 (2009)

6. Sæbø, Ø., Rose, J., Skiftenes Flak, L.: The shape of eParticipation: Characterizing an emerging research area. Government Information Quarterly 25, 400-428 (2008)

7. United Nations: E-Government Survey 2012: E-Government for the People, United Nations, New York (2012)

8. Jackson, K.D.: Bureaucratic polity: A theoretical framework for the analysis of power and communications in Indonesia. In: Jackson, K.D., Pye, L.W. (eds.) Political Power and Communications in Indonesia, pp. 3-22. University of California Press, Berkeley (1978)

9. Widianingsih, I., Morrell, E.: Participatory planning in Indonesia: Seeking a new path to democracy. Policy Studies 28, 1-15 (2007)

10. Mignerat, M., Rivard, S.: Positioning the institutional perspective in information systems research. Journal of Information Technology 24, 369-391 (2009)

11. Scholl, H.J.: Involving salient stakeholders Beyond the technocratic view on change. Action Research 2, 277-304 (2004)

12. Flak, L.S., Rose, J.: Stakeholder governance: Adapting stakeholder theory to egovernment. Communications of the Association for Information Systems 16, 642-664 (2005) 
13. Scott, W.R.: Institutions and Organizations: Ideas and Interest. Sage, Thousand Oaks (2008)

14. DiMaggio, P.J., Powell, W.W.: The iron cage revisited: Institutional isomorphism and collective rationality in organizational fields. American Sociological Review 48, 147-160 (1983)

15. Thornton, P.H., Ocasio, W.: Institutional Logics. In: Greenwood, R., Oliver, C., Suddaby, R., Sahlin-Andersson, K. (eds.) The SAGE Handbook of Organizational Institutionalism, pp. 99-129. Sage, London (2008)

16. Scott, W.R.: The adolescence of Institutional Theory. Administrative Science Quarterly $32,493-511$ (1987)

17. DiMaggio, P.J.: Interest and agency in institutional theory. In: Zucker, L.G. (ed.) Institutional Patterns and Organizations: Culture and Environment, Ballinger, Cambridge, MA, pp. 3-21 (1988)

18. Battilana, J., Leca, B., Boxenbaum, E.: How actors change institutions: Towards a theory of institutional entrepreneurship. The Academy of Management Annals 3, 65-107 (2009)

19. Avgerou, C.: IT and organizational change: an institutionalist perspective. Information Technology \& People 13, 234-262 (2000)

20. Dacin, M.T., Goodstein, J., Scott, W.R.: Institutional theory and institutional change: Introduction to the special research forum. Academy of Management Journal 45, 45-56 (2002)

21. Selznick, P.: Institutionalism "old" and "new”. Administrative Science Quarterly 41, 270277 (1996)

22. Wahid, F., Sein, M.K.: Institutional entrepreneurs: The driving force in institutionalization of public systems in developing countries. Transforming Government: People, Process and Policy 7 (2013)

23. Gil-Garcia, J.R., Martinez-Moyano, I.J.: Understanding the evolution of e-government: The influence of systems of rules on public sector dynamics. Government Information Quarterly 24, 266-290 (2007)

24. Kim, S., Kim, H.J., Lee, H.: An institutional analysis of an e-government system for anticorruption: The case of OPEN. Government Information Quarterly 26, 42-50 (2009)

25. Mitchell, R.K., Agle, B.R., Wood, D.J.: Toward a theory of stakeholder identification and salience: Defining the principle of who and what really counts. Academy of Management Review 22, 853-886 (1997)

26. Sæbø, Ø., Flak, L.S., Sein, M.K.: Understanding the dynamics in e-Participation initiatives: Looking through the genre and stakeholder lenses. Government Information Quarterly $28,416-425$ (2011)

27. Axelsson, K., Melin, U., Lindgren, I.: Public e-services for agency efficiency and citizen benefit-Findings from a stakeholder centered analysis. Government Information Quarterly 30, 10-22 (2012)

28. Cavaye, A.L.M.: Case study research: A multi - faceted research approach for IS. Information Systems Journal 6, 227-242 (1996)

29. Dibbern, J., Winkler, J., Heinzl, A.: Explaining variations in client extra costs between software projects offshored to India. MIS Quarterly 32, 333 (2008)

30. Eisenhardt, K.M.: Building theories from case study research. Academy of Management Review 14, 532-550 (1989)

31. Selznick, P.: Leadership in Administration. Harper and Row, New York (1957)

32. Clegg, S.: The state, power, and agency: Missing in action in institutional theory? Journal of Management Inquiry 19, 4-13 (2010) 